\title{
Case Report with Review of the Literature: Uveal Melanoma in a Patient with Carney Complex - Another Rare Component of the Syndrome?
}

\author{
Diva R. Salomão a, b Cristiane M. Idab, c Patricia T. Greipp ${ }^{c} \quad$ J. Aidan Carney ${ }^{d}$ \\ ${ }^{a}$ Department of Ophthalmology, Mayo Clinic, Rochester, MN, USA; ${ }^{b}$ Division of Anatomic Pathology, \\ Department of Laboratory Medicine and Pathology, Mayo Clinic, Rochester, MN, USA; ' Division of Laboratory \\ Genetics and Genomics, Mayo Clinic, Rochester, MN, USA; ${ }^{d}$ Emeritus Member, Mayo Clinic, Rochester, MN, USA
}

\section{Established Facts}

- Carney complex (CNC) is a rare autosomal dominant syndrome characterized by pigmented lesions of the skin, mucosa, myxomatous tumors and multiple other endocrine and non-endocrine neoplasms.

- A number of ocular lesions have been described in patients with CNC.

\section{Novel Insights}

- This is the second reported case of uveal melanoma arising in a patient with CNC.

- This case should raise awareness for the possibility of another tumor associated with Carney syndrome.

\section{Keywords}

Carney complex · Carney syndrome - Uveal melanoma ·

Ocular tumor · Chromosomal microarray

\begin{abstract}
A 74-year-old woman with Carney complex (CNC) and complaints of poor vision was found, on ophthalmic examination, to have a pigmented tumor involving the peripheral choroid and ciliary body in her right eye. The eye was enucleated and showed a ciliochoroidal melanoma with marked
\end{abstract}

pleomorphism. The tumor did not recur or metastasize after almost 10 years of follow-up, and the patient died of unrelated causes. Molecular studies revealed a complex genome with multiple whole-chromosome losses including monosomy of chromosomes 1, 2 (including loss of CNC2 at 2p16), 14,17 (including loss of a copy of PRAKA1 at 17q24.2), 18, 19, 21,22 , and $X$. No monosomy 3 was observed. This is only the second case of uveal melanoma in a patient with CNC, raising the possibility that this might represent a rare component of this syndrome.

(c) 2020 S. Karger AG, Basel karger@karger.com

(C) 2020 S. Karger AG, Basel

www.karger.com/oop

Karger ${ }^{\prime}=$
Dr. Diva R. Salomão

200 First Avenue, SW

Rochester, MN 55905 (USA)

salomao.diva@mayo.edu 


\section{Introduction}

In 1985, Carney et al. [1, 2] described a rare genetic syndrome characterized by myxomas, spotty pigmentation, and endocrine overactivity affecting both sexes equally and transmitted as an autosomal dominant trait. The myxomas occur in a number of locations, including the heart [3], breast, skin, eyelid [4, 5], and conjunctiva $[6,7]$. The spotty pigmentation observed in these patients affects the skin, conjunctiva, and vermilion border of the lip. The endocrine overactivity includes Cushing syndrome, acromegaly, and sexual precocity. The combination of these lesions/findings was termed Carney complex (CNC) by Bain [8] and later Carney syndrome by the MIM (Mendelian Inheritance in Man). Following its initial description, a number of neoplasms (psammomatous melanotic schwannoma [9], epithelioid blue nevus [10], and thyroid follicular tumors [11]) were added to this syndrome. Inactivation of the PRKAR1A tumor suppressor gene on chromosome 17 at 17q24.2 $[12,13]$ was found to be implicated in the pathogenesis of this disease, and a second locus on chromosome 2 at 2p16p16 (CNC2 locus) has been described in tumors from patients without PRKAR1A inactivation [14]. Herein, we describe the second case of uveal melanoma in a patient with $\mathrm{CNC}$ and the molecular findings observed in that tumor.

\section{Case Report}

A Mayo Clinic patient with CNC, whom we were following, alerted Dr. Carney about her mother's ocular tumor. The Carney syndrome had been transmitted through four generations in her family. Although her mother had not been seen at the Mayo Clinic, we obtained her medical records and pathology material to review from another institution where the patient had been treated.

The daughter reported that her mother, now deceased, had a history of poor vision for a very long time for which she wore glasses for more than 30 years. When questioned about presence of cutaneous and mucosal pigmented lesions, she remembered a pigmented lesion her mother had in the medial canthus of the right eye (Fig. 1a), present for many years, which had been excised during a right cataract extraction procedure, but a pathology report was unavailable. Her mother also had a pigmented spot at the center of the vermilion border of her upper lip. Her mother's past medical history included three other surgical procedures, including the removal of a lipoma on her back at the age of 18 months, right mastectomy for intraductal mammary carcinoma at the age of 52 years, and hysterectomy with bilateral oophorectomy and salpingectomy for menorrhagia at the age of 62 years.

Medical records were available for the patient, the mother, a 74-year-old woman, from her hospitalization at another institution in August 2004 to evaluate symptoms of right amaurosis fugax and disequilibrium. On physical exam at the hospital admission, a possible intraocular mass was visualized in the right eye. Workup included MRI of the brain and orbits. It revealed a bright gradientecho $0.5-\mathrm{cm}$ lesion in the right globe superiorly, with enhancement, suggestive of an intraocular melanoma. The brain MRI showed changes of diffuse small vessel disease, a subacute ischemic infarct in the midbrain, and a small chronic frontal infarct. The remainder of the workup was negative for cardiac myxoma or other neoplasms. Her endocrine testing evaluation was within normal ranges. The patient was advised to follow up with the ophthalmology department after hospital dismissal.

The patient returned in December 2004. She still had visual symptoms in the right eye, presence of a shadow, but no new complaints. Her external exam was unremarkable except for the surgical absence of the right caruncle. Her visual acuity was 20/60 in both eyes, and intraocular pressure was $16 \mathrm{~mm} \mathrm{Hg}$ in the right eye and $19 \mathrm{~mm} \mathrm{Hg}$ in the left eye. Intraocular lens were present bilaterally. The left eye fundus exam was normal, but the right fundus exam revealed a dome-shaped pigmented ciliochoroidal mass in the superior region consistent with uveal melanoma (Fig. 1b). The tumor had grown from 5.0 to $6.5 \mathrm{~mm}$ in diameter in the past few months. The patient agreed to enucleation of the right eye.

The patient's daughter reported that her mother died of natural causes at the age of 83 years, with no evidence of recurrent or metastatic disease. An autopsy was not performed.

\section{Pathology Findings}

The right globe was received in the laboratory in formalin. It measured $24.5 \times 24.5 \times 25 \mathrm{~mm}$ and had an attached 8 - $\mathrm{mm}$ segment of optic nerve. The cornea was clear. Gross examination revealed a transillumination defect between 11:00 and 1:30 o'clock, starting anteriorly at the limbus and extending $16.5 \mathrm{~mm}$ posteriorly. The globe, sectioned in the vertical plane, exposed a lobular, heterogeneous, dome-shaped mass in the choroid superiorly, measuring $5 \mathrm{~mm}$ in maximum height and $11 \mathrm{~mm}$ at its largest base diameter. The ciliary body was partially involved by tumor.

Microscopic examination showed a malignant uveal melanoma, epithelioid type, involving the peripheral choroid and ciliary body with invasion of the superficial sclera. The neoplastic cells were very pleomorphic, arranged in sheets, and they had abundant vacuolated cytoplasm and poorly defined cell membrane. Nuclei were enlarged with irregular nuclear membranes, open chromatin, and prominent magenta-colored nucleoli. Several cells had intranuclear inclusions, and a few had intracytoplasmic melanin pigment (Fig. 1c). Pigment-laden macrophages were interspersed among the tumor cells and a few lymphocytes were seen at the periphery of the tumor mass. Mitotic figures were rare; two mitoses were found in 40 high-power fields. There was no tumor necrosis. Numerous large blood vessels and vascular lakes were present (Fig. 1d). A microvascular pattern characterized by loops or networks of cells was not found. The Bruch's membrane overlying the tumor was intact. Numerous drusen, retinal pigment epithelium proliferation, and a small amount of subretinal fluid were observed. On immunohistochemical studies, the tumor cells were positive for Melan A and HMB45 and negative for S100 and SOX10. The neoplastic cells were negative for BAP1, consistent with the loss of BAP1 protein expression. The tumor cells were also negative for PRKAR1A immunostain, consistent with the loss of PRKAR1A protein expression (Fig. 1e). The pathologic diagnosis was that of a ciliochoroidal malignant melanoma, epithelioid type with marked cellular atypia. 


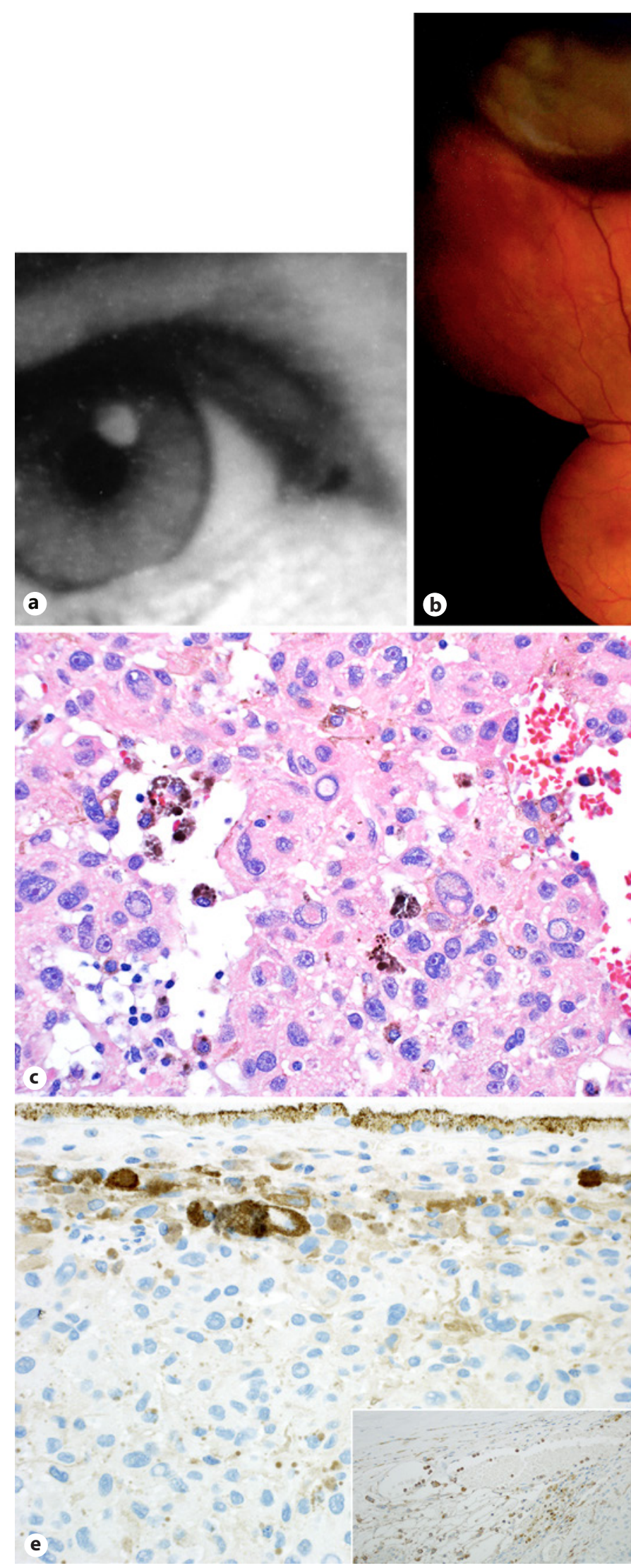

Fig. 1. Clinical image of the patient's right eye shows a pigmented lesion in the caruncle (a). Fundus image of her right eye revealed an intraocular tumor with features of uveal melanoma (b). Highpower microscopic image shows epithelioid cells with prominent nuclear pleomorphism and numerous cells with intranuclear inclusions (hematoxylin-eosin stain; original magnification $\times 400$ ) (c). Low-power microscopic image shows a choroidal uveal melanoma associated with retinal detachment, RPE changes, and intratumoral vascular lakes (hematoxylin-eosin stain; original magnification $\times 100)(\mathbf{d})$. The tumor cells are negative for PRKA1A immunostaining reflecting loss of PRKA1A protein expression $($ PRKA1A immunostain; original magnification $\times 400)(\mathbf{e})$. The inset shows PRKA1A protein expression in the mesenchymal cells in the choroidal tissue adjacent to the tumor mass (PRKA1A immunostain; original magnification $\times 200$ ).

Uveal Melanoma in a Carney Complex

Ocul Oncol Pathol 2020;6:311-317 


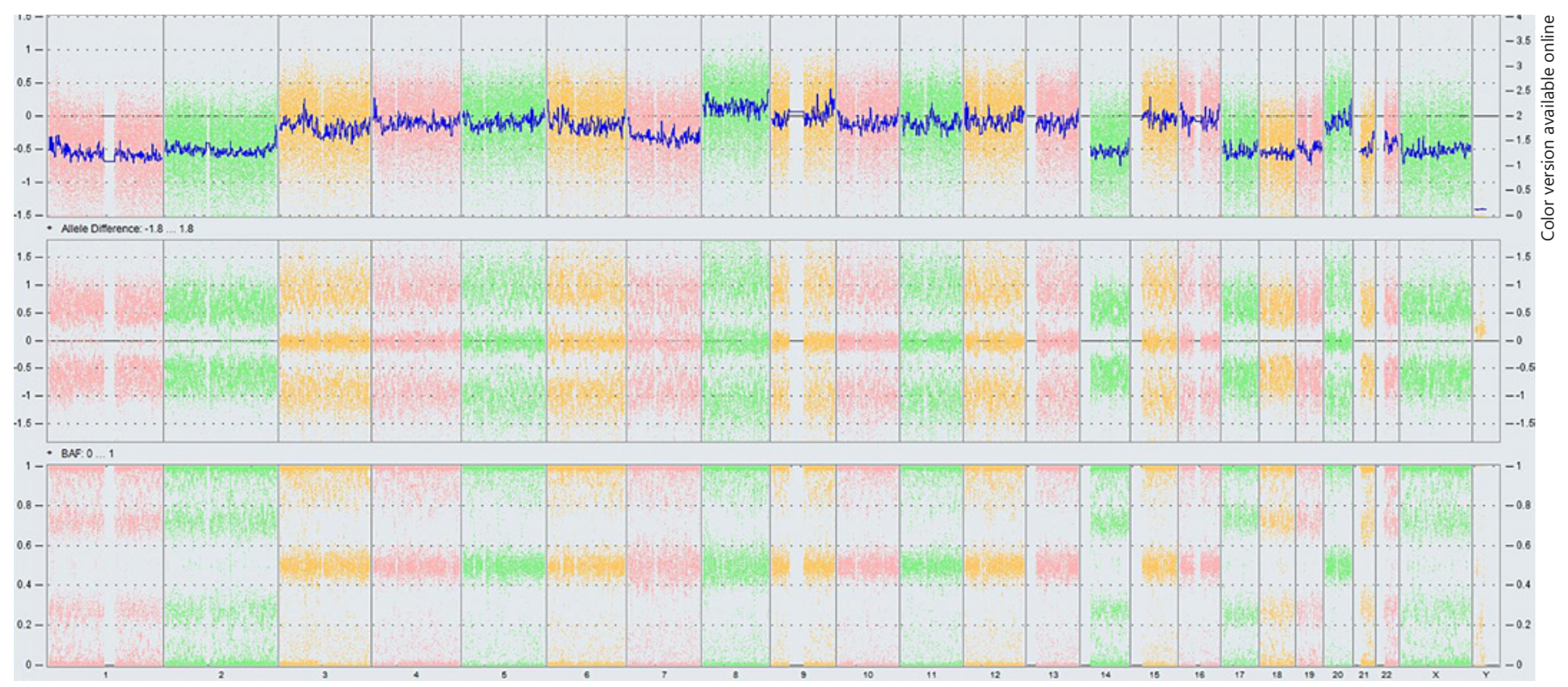

Fig. 2. Chromosomal microarray: whole-genome view shows whole-chromosome losses (monosomies) involving chromosomes 1, 2 (including the SF3B1 gene), 14 (including the KTN1 gene), 17 (including the PRKAR1A and TP53 genes), 18, 19, 21, 22 (including the TTC28 gene), and X (including the EIF1AX gene); low-level monosomy 7 and trisomy 8 , without evidence of monosomy 3 or chromosome 6 gains/losses.

Table 1. Summary of all chromosomal changes identified by the chromosomal microarray analysis in this case

Monosomy of chromosome 1 (loss of CDKN2C, ARID1A, PARP1)

Monosomy of chromosome 2 (loss of CNC2, SF3B1, MSH2, ERBB4)

Monosomy of chromosome 14 (loss of $M M P 14$ )

Monosomy of chromosome 17 (loss of TP53, NF1, SMARCA4, PRKAR1A)

Monosomy of chromosome 18 (loss of GATA6, SMAD2, SMAD4, BCL2)

Monosomy of chromosome 19 (loss of SMARCA4, STK11)

Monosomy of chromosome 21 (loss of TMPRSS2, ERG, RUNX1, U2AF1)

Monosomy of chromosome 22 (loss of RNF185, CHEK2, NF2, MAPK1 [ERK2], SMARCB1, CRKL, BCR, EP300)

Monosomy of chromosome X (loss of EIF1AX, ATRX, ELK1, DDX3X)

A subclonal population of nuclei showed monosomy 7 and trisomy 8 . No evidence of monosomy of chromosome 3.

\section{Molecular Studies}

The tissue area with the highest tumor percent (proportion of tumor cell nuclei relative to all cell nuclei) was delineated for tumor enrichment in hematoxylin-eosin-stained slide from the 15-year-old formalin-fixed, paraffin-embedded (FFPE) enucleation specimen. Tumor percentage within the delineated area was estimated as greater than $80 \%$. The delineated enriched tumor area was manually macrodissected from $5-\mu \mathrm{m}$ unstained sections matched with the corresponding hematoxylin-eosin-stained section, and DNA was extracted using the QIAamp ${ }^{\circledR}$ DSP DNA FFPE Tissue Kit (Qiagen Inc., Germantown, MD, USA) as previously described [15]. Chromosomal microarray analysis was performed using the OncoScan FFPE Assay Kit (Thermo Fisher, Santa Clara,
CA, USA) according to clinically validated protocols [16]. The genome-wide functional resolution of this platform for non-mosaic deletions and duplications is approximately 500 kilobases. Findings interpreted as clinically significant include deletions larger than 1 megabase, duplications larger than two megabases, and copy neutral loss of heterozygosity larger than 10 megabases. No residual tumor tissue was available for mutation testing.

Chromosomal microarray data were slightly noisy, most likely due to the age of the tumor specimen tested. However, the copy number profile revealed a clear hypoploid copy number state (Fig. 2). There were multiple whole-chromosome losses (i.e., monosomies), resulting in a chromosome count of 37. A summary of the chromosomal changes is shown in Table 1 . The known and poten- 
tially relevant genes for a case of uveal melanoma are listed in parentheses: chromosomes 1, 2 (including the CNC2 and SF3B1 genes), 14 (including the KTN1 gene), 17 (including the PRKAR1A gene), $18,19,21,22$ (including the TTC28 gene), and X (including the EI$F 1 A X$ gene). Low-level monosomy 7 and trisomy 8 (including the MYC gene) were also noted, suggesting the presence of a subclonal cell population. Of note, there was no evidence of monosomy or loss of heterozygosity of chromosome 3 (i.e., the tumor had disomy 3 ), wherein the BAP1 gene is located, or chromosome 6 gains/losses.

\section{Discussion}

CNC is a rare autosomal dominant syndrome characterized by myxomas, cutaneous and mucosal pigmented lesions, and multiple endocrine neoplasms [17]. Although pigmented lesions of the skin and mucosa are common in patients with $\mathrm{CNC}$ and considered major diagnostic criteria, these are usually benign, and the associated risk of cutaneous melanoma is considered low. This case likely represents the second case of uveal melanoma occurring in a patient with CNC. The other case, on a 16-year-old female, which was published as an abstract only with no histopathologic images to allow comparisons, did not have molecular studies performed, and follow-up was not available [18].

The ophthalmic manifestation of CNC was first described by Kennedy et al. [4] and characterized by the findings of facial and eyelid pigmented lesions (lentigines) in $70 \%$ of the patients, pigmented lesions on the caruncle or conjunctival semilunar fold in $27 \%$, and eyelid myxomas in $16 \%$. The authors emphasized the importance of an early recognition of these findings, as these could precede more serious components of the syndrome, such as the presence of an asymptomatic cardiac myxoma [6]. A few case reports followed confirming those associations $[19,20]$. Other ocular lesions seen in patients with CNC are conjunctival myxomas $[7,21,22]$ and rarely uveal melanotic schwannomas [23].

Although our patient did not undergo germline testing, she fulfilled major clinical diagnostic criteria for CNC [17]. Only her ocular tumor was evaluated by chromosomal microarray. Therefore, the chromosomal abnormalities observed in this case are considered somatic (i.e., tumor-specific) as opposed to germline (i.e., constitutional) copy number abnormalities. Additionally, large germline deletions, including the PRKAR1A gene seen in CNC patients, are typically subchromosomal (i.e., partial, not involving the whole chromosome) [24, 25], whereas the observed monosomy 17 in the tumor we report most likely accounts for the somatic loss of the wild-type allele

Uveal Melanoma in a Carney Complex

Patient of the PRKAR1A gene in keeping with the Knudson's two-hit model that has been demonstrated in other CNC tumors [12, 13, 24].

Of interest was the observation of marked cellular pleomorphism in our case and also the other uveal melanoma reported in the young patient with $\mathrm{CNC}$; although with this report being an abstract only, there were no histopathologic images to allow a good correlation with our present case. Presence of cytoplasmic vacuoles and numerous intranuclear cytoplasmic inclusions, seen in the tumor in our patient, are unusual findings in uveal melanoma. Despite a number of variables observed in our case that could indicate a poor prognosis (epithelioid cell morphology, tumor size and ciliary body involvement, and loss of BAP1 protein expression), our patient survived for another 10 years with no evidence of metastatic disease. Since her tumor was not very mitotically active, this degree of pleomorphism could perhaps be of degenerative nature or explained by the very complex chromosomal abnormalities that were detected in her tumor cells.

The copy number profile of our patient's uveal melanoma is distinct from profiles previously reported in other cases of uveal melanoma, wherein whole-arm chromosomal losses other than monosomy 3 are rare or have not been observed [26-31]. This tumor did not show prognostically relevant genomic copy number alterations of uveal melanoma that involve chromosomes 3, 6, and 8 (except for low-level trisomy 8 ) and would be classified as a disomy 3 tumor. The observed BAP1 protein expression loss by immunohistochemistry, which typically occurs in tumors with monosomy 3 , has also been described in the context of disomy 3 as seen in our patient's tumor [32, 33]. We hypothesize that the observed BAP1 loss of protein expression may be a result of a loss-of-function alteration (e.g., single nucleotide variant, insertion-deletion event, copy number variation below the functional resolution of the chromosomal microarray or a balanced translocation involving BAP1, which is undetectable by chromosomal microarray) or promoter hypermethylation involving the BAP1 gene. Unfortunately, follow-up studies to investigate the underlying molecular event leading to the loss of BAP1 expression identified by immunohistochemistry were not possible as no residual tissue was available. Of note, at least one allele of the EIF1AX tumor suppressor gene, which is associated with favorable prognosis in disomy 3 uveal melanoma [28], was lost in this tumor as a part of loss of one chromosome X. Taken altogether, even though unusual, the identified copy number changes would suggest an overall favorable prognosis in this case. 
In summary, we report the second case of uveal melanoma occurring in a patient with $\mathrm{CNC}$. This case raises awareness for the possibility of yet another tumor associated with Carney syndrome.

\section{Acknowledgement}

The authors thank Dr. Nasreen Syed at the F.C. Blodi Eye Pathology Laboratory, University of Iowa Hospitals and Clinic, for providing the unstained slides from the enucleation specimen that allowed us to perform additional immunostains and molecular testing in this case.

\section{Statement of Ethics}

This study was granted exempt status by our Institutional Review Board.

\section{Disclosure Statement}

The authors have no conflicts of interest to declare.

\section{Funding Sources}

No funding was obtained to support this study.

\section{Author Contributions}

D.R.S. and J.A.C.: substantial contributions to the conception and design of the work; all authors: acquisition, analysis, or interpretation of data for the work; J.A.C. and D.R.S.: drafting the work; all authors: revising the work critically for important intellectual content; all authors: final approval of the version to be published; and all authors: agreement to be accountable for all aspects of the work in ensuring that questions related to the accuracy or integrity of any part of the work are appropriately investigated and resolved.

\section{References}

1 Carney JA, Gordon H, Carpenter PC, Shenoy BV, Go VL. The complex of myxomas, spotty pigmentation, and endocrine overactivity. Medicine (Baltimore). 1985 Jul;64(4):270-83.

2 Carney JA, Hruska LS, Beauchamp GD, Gordon H. Dominant inheritance of the complex of myxomas, spotty pigmentation, and endocrine overactivity. Mayo Clin Proc. 1986 Mar; 61(3): 165-72.

3 Barlow JF, Abu-Gazeleh S, Tam GE, Wirtz PS, Ofstein LC, O'Brien CP, et al. Myxoid tumor of the uterus and right atrial myxomas. S D J Med. 1983 Jul;36(7):9-13.

4 Kennedy RH, Waller RR, Carney JA. Ocular pigmented spots and eyelid myxomas. Am J Ophthalmol. 1987 Nov; 104(5):533-8.

5 Tsilou ET, Chan CC, Sandrini F, Rubin BI, Shen DF, Carney JA, et al. Eyelid myxoma in Carney complex without PRKAR1A allelic loss. Am J Med Genet A. 2004 Nov;130A(4): 395-7.

6 Kennedy RH, Flanagan JC, Eagle RC Jr, Carney JA. The Carney complex with ocular signs suggestive of cardiac myxoma. Am J Ophthalmol. 1991 Jun;111(6):699-702.

7 Ramaesh K, Wharton SB, Dhillon B. Conjunctival myxoma, Zollinger-Ellison syndrome and abnormal thickening of the interatrial septum: a case report and review of the literature. Eye (Lond). 2001 Jun;15(Pt 3):309_ 12.

8 Bain J. "Carney's complex”. Mayo Clin Proc. 1986 Jun;61(6):508.

9 Carney JA. Psammomatous melanotic schwannoma. A distinctive, heritable tumor with special associations, including cardiac myxoma and the Cushing syndrome. Am J Surg Pathol. 1990 Mar;14(3):206-22.
10 Carney JA, Ferreiro JA. The epithelioid blue nevus. A multicentric familial tumor with important associations, including cardiac myxoma and psammomatous melanotic schwannoma. Am J Surg Pathol. 1996 Mar;20(3): 259-72.

11 Carney JA, Lyssikatos C, Seethala RR, Lakatos $\mathrm{P}$, Perez-Atayde A, Lahner H, et al. The Spectrum of Thyroid Gland Pathology in Carney Complex: The Importance of Follicular Carcinoma. Am J Surg Pathol. 2018 May;42(5): 587-94.

12 Kirschner LS, Carney JA, Pack SD, Taymans SE, Giatzakis C, Cho YS, et al. Mutations of the gene encoding the protein kinase A type I-alpha regulatory subunit in patients with the Carney complex. Nat Genet. 2000 Sep;26(1): 89-92.

13 Kirschner LS, Sandrini F, Monbo J, Lin JP, Carney JA, Stratakis CA. Genetic heterogeneity and spectrum of mutations of the PRKAR1A gene in patients with the carney complex. Hum Mol Genet. 2000 Dec;9(20):303746.

14 Matyakhina L, Pack S, Kirschner LS, Pak E, Mannan P, Jaikumar J, et al. Chromosome 2 (2p16) abnormalities in Carney complex tumours. J Med Genet. 2003 Apr;40(4):268-77.

15 Ida CM, Vrana JA, Rodriguez FJ, Jentoft ME, Caron AA, Jenkins SM, et al. Immunohistochemistry is highly sensitive and specific for detection of BRAF V600E mutation in pleomorphic xanthoastrocytoma. Acta Neuropathol Commun. 2013 May;1(1):20.

16 Gliem TJ, Aypar U. Development of a Chromosomal Microarray Test for the Detection of Abnormalities in Formalin-Fixed, Paraffin-Embedded Products of Conception Specimens. J Mol Diagn. 2017 Nov;19(6):843-7.
17 Correa R, Salpea P, Stratakis CA. Carney complex: an update. Eur J Endocrinol. 2015 Oct;173(4):M85-97.

18 Farook S, Gibson C, Davis J. Choroidal malignant melanoma in a patient with Carney complex. Endocrine Abstracts. 2010;21:201.

19 Chinchurreta-Capote A, Trueba A, Hernández FJ, Piñas P, López S, Tena ME, et al. [Ocular findings in Carney complex]. Arch Soc Esp Oftalmol. 2006 Dec;81(12):709-11.

20 Cohen C, Turner ML, Stratakis CA. Pigmented lesions of the conjunctiva in Carney's complex. J Am Acad Dermatol. 2000 Jan;42(1 Pt 1):145.

21 Milman T, Salomao DR, Ida CM, Capiz Correa DR, Grossniklaus HE, Zhang Q, et al. Conjunctival Myxoid Lesions: ClinicalPathologic Multiparametric Analysis, Including Molecular Genetics (An American Ophthalmological Society Thesis). Am J Ophthalmol 2019;205:115-31.

22 Xiong MJ, Dim DC. Conjunctival myxoma: a synopsis of a rare ocular tumor. Arch Pathol Lab Med. 2015 May;139(5):693-7.

23 Saavedra E, Singh AD, Sears JE, Ratliff NB. Plexiform pigmented schwannoma of the uvea. Surv Ophthalmol. 2006 Mar-Apr;51(2): 162-8.

24 Iwata T, Tamanaha T, Koezuka R, Tochiya M, Makino H, Kishimoto I, et al. Germline deletion and a somatic mutation of the PRKAR1A gene in a Carney complex-related pituitary adenoma. Eur J Endocrinol. 2015 Jan; 172(1):K5-10.

25 Salpea P, Horvath A, London E, Faucz FR, Vetro A, Levy I, et al. Deletions of the PRKAR1A locus at 17q24.2-q24.3 in Carney complex: genotype-phenotype correlations and implications for genetic testing. J Clin Endocrinol Metab. 2014 Jan;99(1):E183-8. 
26 Anbunathan H, Verstraten R, Singh AD, Harbour JW, Bowcock AM. Integrative Copy Number Analysis of Uveal Melanoma Reveals Novel Candidate Genes Involved in Tumorigenesis Including a Tumor Suppressor Role for PHF10/BAF45a. Clin Cancer Res. 2019 Aug;25(16):5156-66.

27 Johansson P, Aoude LG, Wadt K, Glasson WJ, Warrier SK, Hewitt AW, et al. Deep sequencing of uveal melanoma identifies a recurrent mutation in PLCB4. Oncotarget. 2016 Jan; 7(4):4624-31.

28 Robertson AG, Shih J, Yau C, Gibb EA, Oba J, Mungall KL, Hess JM, Uzunangelov V, Walter V, Danilova L, Lichtenberg TM, Kucherlapati M, Kimes PK, Tang M, Penson A, Babur O, Akbani R, Bristow CA, Hoadley KA, Iype L, Chang MT, TCGA Research Network; Cherniack AD, Benz C, Mills GB, Ver- haak RG, Griewank KG, Felau I, Zenklusen JC, Gershenwald JE, Schoenfield L, Lazar AJ, Abdel-Rahman MH, Roman-Roman S, Stern $\mathrm{MH}$, Cebulla CM, Williams MD, Jager MJ, Coupland SE, Esmaeli B, Kandoth C, Woodman SE: Integrative Analysis Identifies Four Molecular and Clinical Subsets in Uveal Melanoma. Cancer Cell 2017;32:204-220.e215. https://doi.org/10.1016/j.ccell.2017.07.003.

29 Royer-Bertrand B, Torsello M, Rimoldi D, El Zaoui I, Cisarova K, Pescini-Gobert R, et al. Comprehensive Genetic Landscape of Uveal Melanoma by Whole-Genome Sequencing. Am J Hum Genet. 2016 Nov;99(5):1190-8.

30 van Engen-van Grunsven AC, Baar MP, Pfundt R, Rijntjes J, Küsters-Vandevelde HV, Delbecq AL, et al. Whole-genome copy-number analysis identifies new leads for chromosomal aberrations involved in the oncogene- sis and metastastic behavior of uveal melanomas. Melanoma Res. 2015 Jun;25(3):200-9.

31 Yavuzyigitoglu S, Drabarek W, Smit KN, van Poppelen N, Koopmans AE, Vaarwater J, et al.; Rotterdam Ocular Melanoma Study Group. Correlation of Gene Mutation Status with Copy Number Profile in Uveal Melanoma. Ophthalmology. 2017 Apr;124(4):573-5.

32 Glasgow BJ, McCannel TA. Correlation of Immunocytochemistry of BRCA1-associated Protein-1 (BAP1) With Other Prognostic Markers in Uveal Melanoma. Am J Ophthalmol. 2018 May;189:122-6.

33 van de Nes JA, Nelles J, Kreis S, Metz CH, Hager T, Lohmann DR, et al. Comparing the Prognostic Value of BAP1 Mutation Pattern, Chromosome 3 Status, and BAP1 Immunohistochemistry in Uveal Melanoma. Am J Surg Pathol. 2016 Jun;40(6):796-805. 